\title{
An interpretation of the serum alkaline phosphatase isoenzyme patterns in patients with obstructive liver disease
}

\author{
C. P. PRICE 1 AND H. G. SAMMONS \\ From the Department of Clinical Chemistry, East Birmingham Hospital, Bordesley Green East, \\ Birmingham B9 5ST
}

SYNOPSIS Earlier studies have identified two main isoenzymes of alkaline phosphatase in the sera of patients with obstructive liver disease. This paper reports on a study of these isoenzymes in specific types of liver disease where the pathology in relation to bile duct obstruction is known. The results have been used to support the theory that in biliary obstruction the increase in serum alkaline phosphatase is in part due to regurgitation of the biliary isoenzymes.

The increase in serum alkaline phosphatase activity in patients with diseases of the hepatobiliary system is well known. However, the mechanism of the increase is still in doubt. Early work suggested that the elevation was due to the retention of bone alkaline phosphatase that was normally eliminated in the bile (Gutman, 1959). The idea lost favour when it was recognized that the alkaline phosphatase isoenzymes of bile bore no relation to the isoenzymes seen in sera from patients with bone disease.

More recent theories have suggested that the increase of serum alkaline phosphatase in obstructive liver diseases may be due to the regurgitation of biliary alkaline phosphatase (Hill and Sammons, 1967; Price and Sammons, 1974). There is evidence, however, that bile duct obstruction also leads to an overall increase in the alkaline phosphatase in the liver tissue with possible overspill of this liver tissue isoenzyme into the circulation (Price and Sammons, 1974).

Many workers have shown that experimental bile duct ligation in rats leads to an increase in the liver tissue alkaline phosphatase activity (Kaplan and Righetti, 1970). This increase has been localized in cell membranes using cell fractionation techniques. Histochemical staining techniques have shown the increase in enzyme activity to be localized at the bile canalicular surfaces (Birns et al, 1962).

Our earlier work has shown that the alkaline phosphatase of human bile may be derived from the

${ }^{1}$ Present address: Division of Clinical Pathology, Southampton General Hospital.

Received for publication 1 April 1976 isoenzyme found in liver tissue (Price et al, 1972). Examination of alkaline phosphatase isoenzymes in serum from patients with biliary obstruction shows that there are two main isoenzymes, the liver iso@ enzyme and an abnormal isoenzyme, the latte bearing many similarities to the bile isoenzyme.

To examine the theory that biliary obstruction leads to an increase of liver isoenzyme in the circulation, together with regurgitation of bile isoenzyme, we have studied the isoenzyme patterns of 194 patients with proven hepatobiliary disease. Attention was focused on those patients with either extrahepatic biliary obstruction, metastatic carcinoma or viral hepatitis. It was considered that these disorders represented varying degrees in the obstruction to the flow of bile.

\section{Material and methods}

One hundred and ninety-four adult patients with liver disease were included in this study, with serum alkaline phosphatase levels greater than 90 International Units per litre. Two samples of blood were obtained on separate occasions and the diagnosis was made on the basis of measurement of biochemical parameters together with clinical observations and other diagnostic aids. Nineteen patients with skeletal disorders but no detectable liver disease were also included in the study. Twenty members of the laboratory staff gave samples of blood for the purpose of normal control samples.

Serum alkaline phosphatase activity was determined by means of an AutoAnalyzer technique 
employing disodium phenyl phosphate as substrate (Price and Woodman, 1971).

Electrophoretic studies were performed in polyacrylamide gels by a method described elsewhere (Price and Sammons, 1974). Qualitative visualization of the alkaline phosphatase isoenzymes was by means of incubation with buffered $\beta$-naphthyl phosphate and Fast Blue RR. To assess the quantitative distribution of the isoenzymes after electrophoresis the gels were sliced into $0.5 \mathrm{~cm}$ segments, each segment was homogenized separately in buffered substrate, and the enzyme activity determined by the manual method of Kind and King (1954); $10 \mathrm{mM} \mathrm{Mg}^{++}$was included in the reaction mixture.

Alkaline phosphatase isoenzymes for the purpose of electrophoresis controls were obtained from specimens of postmortem liver and small intestine. The liver tissue was thoroughly washed and cut into small pieces. The small intestine tissue was thoroughly washed and scrapings were taken from the intestinal lumen. Each specimen was homogenized in $0.1 \mathrm{~m}$ Tris- $\mathrm{HCl}$ buffer $\mathrm{pH} \mathrm{7.4}$ in a Waring blender. After centrifugation the supernatants were separated and diluted in heat-inactivated pooled serum to an activity of approximately 140 International Units per litre. A bone isoenzyme control was obtained by using serum from a patient with Paget's disease.

\section{Results}

The patients studied were separated into groups as detailed in table $I$. The isoenzyme patterns in the normal control group consisted mainly of the liver isoenzyme fraction.

\begin{tabular}{|c|c|c|}
\hline Patient group & & $\begin{array}{l}\text { No. of } \\
\text { patients }\end{array}$ \\
\hline $\begin{array}{l}\text { Extrahepatic } \\
\text { obstruction }\end{array}$ & $\begin{array}{l}\text { Bile duct stones, carcinoma of } \\
\text { ampulla of Vater, carcinoma } \\
\text { head of pancreas, all requiring } \\
\text { surgery }\end{array}$ & 37 \\
\hline $\begin{array}{l}\text { Hepatic metastatic } \\
\text { carcinoma }\end{array}$ & $\begin{array}{l}\text { With jaundice } \\
\text { Without jaundice }\end{array}$ & $\begin{array}{l}14 \\
42\end{array}$ \\
\hline Viral hepatitis & & 24 \\
\hline $\begin{array}{l}\text { Other hepatic } \\
\text { disorders }\end{array}$ & $\begin{array}{l}\text { Cirrhosis, cholecystitis, chronic } \\
\text { active hepatitis, Hodgkin's } \\
\text { disease, drug jaundice }\end{array}$ & 77 \\
\hline Skeletal disorders & $\begin{array}{l}\text { Paget's disease, osteomalacia, } \\
\text { skeletal carcinoma }\end{array}$ & 19 \\
\hline
\end{tabular}

Table I Details of patients studied

The serum alkaline phosphatase isoenzyme patterns were found to be similar in all of the patients with liver disease studied, though there were differences in the relative amounts of the isoenzymes. Examples of the isoenzyme patterns are shown in fig 1 . The isoenzyme with a mobility similar to that
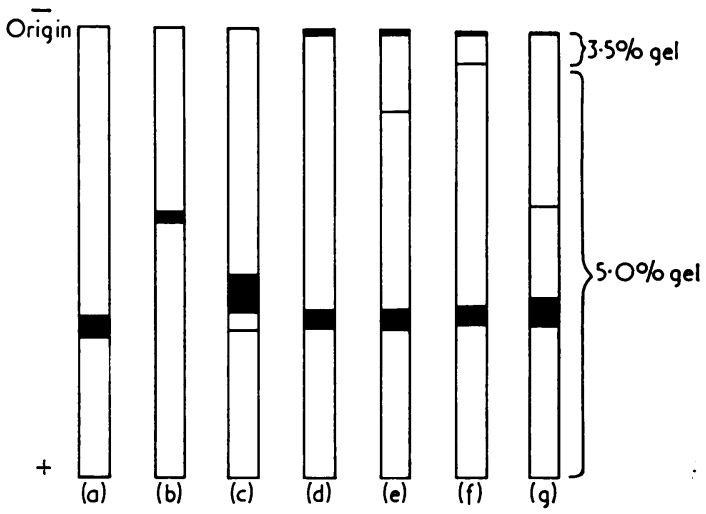

Fig 1 Alkaline phosphatase isoenzyme patterns after polyacrylamide gel electrophoresis of controls and serum from patients with hepatobiliary diseases:

(a) liver tissue; (b) intestinal tissue; (c) serum from patients with Paget's disease; (d) 182 patients; (e) five patients; $(f)$ three patients; and $(g)$ four patients.

of the liver isoenzyme and the isoenzyme remaining at the origin represented the main fractions present.

Several minor bands were seen from time to time but these did not contribute significantly to the total enzyme activity. The data relating to the quantitative distribution of serum alkaline phosphatase isoenzymes therefore refer to the main 'liver' and 'origin' isoenzymes. The 'origin' isoenzyme bears so many similarities to the main isoenzyme in human bile (Price and Sammons, 1974) that we prefer to call it the bile isoenzyme to distinguish it from the main liver isoenzyme. The bile isoenzyme was found in $98 \%$ of all the patients with liver disease. There was no evidence of the bile isoenzyme in any of the control group or in patients with skeletal disorders.

The variation of the total serum alkaline phosphatase activity and that of the bile isoenzyme, as a percentage of the total activity, are shown in figs 2 and 3 respectively. Results are shown only for patients with extrahepatic obstruction, hepatic metastatic carcinoma or viral hepatitis. Except for the group of patients with viral hepatitis the variation in alkaline phosphatase activity in the various patient groups was considerable.

The results of the statistical analysis of the data using Student's $t$ test on unpaired data are shown in table II.

\section{Discussion}

From an initial study of nearly 200 patients with various diseases of the hepatobiliary system, attention was focused on patients with diseases in which the pathology in relation to the flow of bile was well 


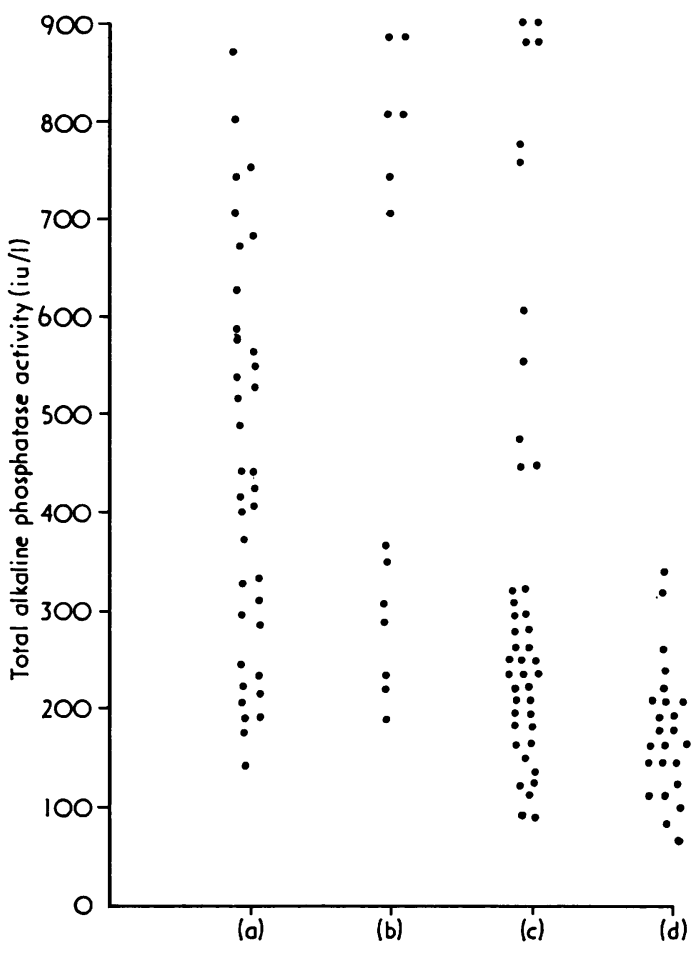

Fig 2 Variation of serum total alkaline phosphatase activities in patients with certain hepatobiliary diseases: (a) extrahepatic obstruction; (b) metastatic carcinoma with jaundice; (c) metastatic carcinoma without jaundice; $(d)$ viral hepatitis.

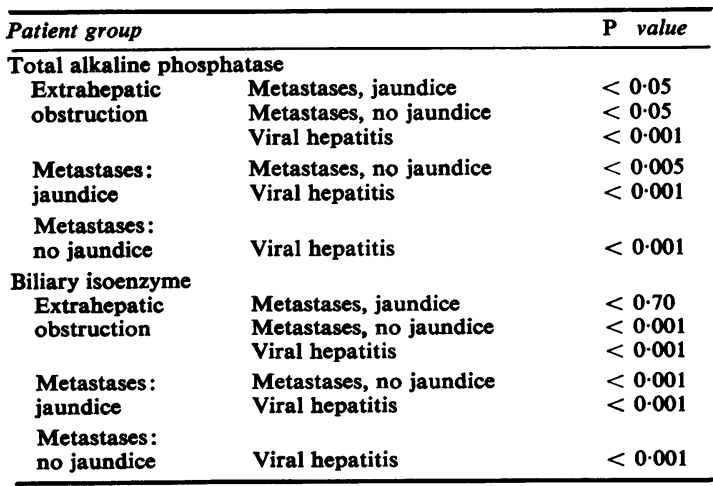

Table II Results of comparison of the mean value by Student's t test indicating significant differences between the levels in different patient groups

defined and understood in an attempt to support a concept that the abnormal alkaline phosphatase isoenzyme in sera from patients with liver disease represents regurgitated bile alkaline phosphatase.

The role of alkaline phosphatase in the liver is not clearly understood and the presence of this enzyme in the bile remains a mystery. Alkaline phosphatase is found on the absorptive cell surfaces in many organs of the body, and a transport function for this enzyme at the bile canalicular surface cannot therefore be ruled out (Posen, 1967). Pekarthy and coworkers (1972) showed that the level of alkaline phosphatase in the rat liver was related to levels of $\vec{O}$ circulating phosphorylcholine in serum although they were unable to demonstrate the enzyme in the rat bile. Our own work (Price et al, 1972) has shown that the alkaline phosphatase present in human bile appears to be a complex of the liver isoenzyme with a phosphatidylcholine moiety.

It has been recognized for several years that in bile duct obstruction there is an increase in the $\sigma$ alkaline phosphatase activity at the biliary canal- $\frac{\text { ? }}{2}$ icular surfaces (Birns et al, 1962). Several workers have been able to demonstrate an increase in the $z$

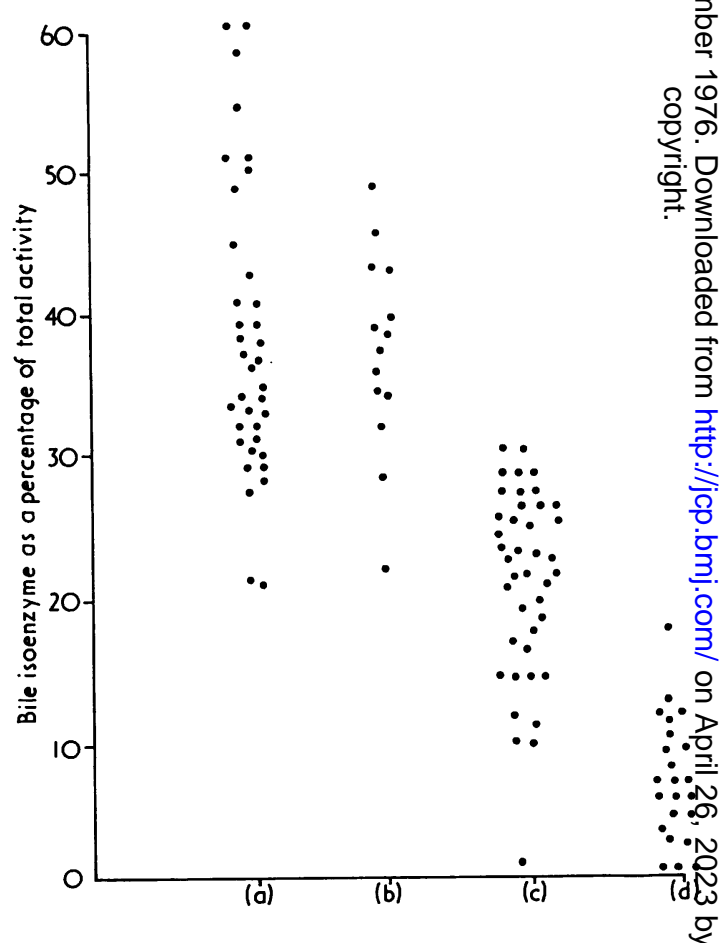

Fig 3 Variation of the abnormal serum alkaline phosphatase isoenzyme activity as a percentage of the total activity in patients with certain hepatobiliary diseases: (a) extrahepatic obstruction; (b) metastatic carcinoma with jaundice; (c) metastatic carcinoma without jaundice; (d) viral hepatitis. 
level of enzyme activity in the liver tissue of animals after bile duct ligation (Börnig et al, 1967; Kaplan and Righetti, 1970; Wootton et al, 1975). Furthermore, Polin et al (1962) found that when the hepatic duct of one lobe of the liver was ligated in dogs, the alkaline phosphatase of serum, bile, and liver tissue all showed a significant increase in activity. It is generally recognized that in biliary obstruction there is an increase in the isoenzyme normally found in the serum and thought to be of hepatic origin, together with the appearance of an abnormal isoenzyme. This abnormal isoenzyme is found at the origin after electrophoresis in starch gel (Chiandussi et al, 1962; Jennings et al, 1970) and acrylamide gel (Walker and Pollard, 1971; Price and Sammons, 1974; Dingjan et al, 1975), and in the $a_{1}$-globulin region after agarose or cellulose acetate electrophoresis (Wieme and Demeulenaere, 1970).

The conclusion to be drawn from earlier studies is that regurgitation of biliary alkaline phosphatase may contribute to the total increase in alkaline phosphatase following obstruction to the flow of bile. Since alkaline phosphatase is not often found in the bile of rats (Kaplan and Righetti, 1970; Pekarthy et al, 1972) it is difficult to apply knowledge gained from ligation of bile ducts in rats directly to the situation of human subjects with biliary obstruction. An attempt has therefore been made to examine the implication of the increase of this abnormal biliary isoenzyme in the blood in relation to the aetiology and nature of the obstruction to the flow of bile.

In extrahepatic biliary obstruction it is recognized that bile is regurgitated into the blood circulation probably through an increased number of canalicular-sinusoidal connections (Wachstein and Meisel, 1958). In cases of hepatic metastatic carcinoma, the biochemical picture can be very varied. Often the raised serum alkaline phosphatase may be the only abnormal finding, and jaundice may present only at a much later stage. The explanation of this observation may be due to obstruction by the metastatic deposit in its infancy to the flow of bile in a small portion of the liver. The remainder of the organ can excrete the regurgitated bilirubin (Popper and Szanto, 1956; Hill and Sammons, 1967) but is unable to excrete a large molecule like alkaline phosphatase. The later onset of jaundice may then reflect obstruction to a larger proportion of the biliary tree. It is unclear how the flow of bile may be affected in cases of viral hepatitis, but it has been suggested (Paton, 1969) that the swollen parenchymal cells may obstruct the small bile channels.

The results presented indicate that there is no clear delineation in the total serum alkaline phosphatase in situations representing varying degrees of obstruc- tion. Only in the case of viral hepatitis is the total enzyme activity significantly different from the other groups studied (table II).

If alkaline phosphatase has a transport function then clearly the level in the liver, and possibly in the bile, will reflect the concentration of substance which it transports. Therefore, in attempting to correlate the amount of regurgitated bile isoenzyme with the degree of biliary obstruction, it is necessary to consider the bile isoenzyme as a proportion of the total activity. The data in fig 3 show that in cases of extrahepatic obstruction the proportion of the regurgitated isoenzyme is significantly higher than in cases of hepatic metastatic carcinoma without jaundice which in turn is higher than in cases of viral hepatitis.

The proportion of regurgitated isoenzyme in cases of hepatic metastatic carcinoma with jaundice is similar to that in patients with extrahepatic obstruction, a situation not entirely unexpected. Four patients admitted to hospital for investigation were found to have raised serum total alkaline phosphatase levels but normal serum bilirubin levels. On admission the proportion of the alkaline phosphatase activity present as the bile isoenzyme ranged between $10 \%$ and $25 \%$ of the total activity. Over a period of weeks these patients became jaundiced and the proportion of bile isoenzyme rose to more than $30 \%$ of the total alkaline phosphatase activity. This suggests that the amount of regurgitated isoenzyme increased as the infiltration progressed.

This discussion has been limited to the appearance of the abnormal alkaline phosphatase isoenzyme in the serum of patients with biliary obstruction of welldefined pathology. Since the isoenzyme was detected in $98 \%$ of all the patients with liver disease studied, regurgitation of bile may occur in all types of liver disease. However, the value of this isoenzyme as an indicator of biliary regurgitation cannot be fully appreciated because in many types of liver disease the pathology in relation to impairment of the flow of bile is not well defined.

It is concluded from the data presented (and earlier reports) that the abnormal alkaline phosphatase isoenzyme seen in sera from patients with liver disease represents regurgitated biliary enzyme. The proportion of regurgitated enzyme is a reflection of the degree of biliary obstruction which is either intraor extra-hepatic. The level of total alkaline phosphatase represents the regurgitation of biliary enzyme plus the release of liver alkaline phosphatase probably in association with increased synthesis of this enzyme within the liver.

\section{References}

Birns, M., Masek, B., and Auerbach, O. (1962). The effects 
of experimental acute biliary obstruction and release on the rat liver. Amer. J. Path., 40, 95-111.

Börnig, H., Stepán, J., Horn, A., Giertler, R., Thiele, G., and Vecbrek, B. (1967). Phosphatases. V. Intrazelluläre Verteilung der Isoenzyme der alkalischen Phosphatase der Rattenleber und ihr Verhalten nach Interbindung des Ductus choledochus. Hoppe-Seyler's Z. physiol. Chem., 348, 1311-1318.

Chiandussi, L., Greene, S. F., and Sherlock, S. (1962). Serum alkaline phosphatase fractions in hepatobiliary and bone diseases. Clin. Sci., 22, 425-434.

Dingjan, P. G., Postma, T., and Stroes, J. A. P. (1975). Quantitative differentiation of human serum alkaline phosphatase isoenzymes with polyacrylamide disc gel electrophoresis. Z. klin. Chem., 11, 167-171.

Gutman, A. B. (1959). Serum alkaline phosphatase activity in diseases of the skeletal and hepatobiliary systems. Amer. J. Med., 27, 875-901.

Hill, P. G. and Sammons, H. G. (1967). An assessment of $5^{\prime}$-nucleotidase as a liver-function test. Quart. J. Med., 36, 457-468.

Jennings, R. C., Brocklehurst, D., and Hirst, M. (1970). A comparative study of alkaline phosphatase enzymes using starch-gel electrophoresis and Sephadex gel-filtration with special reference to high molecular weight enzymes. Clin. chim. Acta, 30, 509-517.

Kaplan, M. M. and Righetti, A. (1970). Induction of rat liver alkaline phosphatase: the mechanism of the serum elevation in bile duct obstruction. J. clin. Invest., 49, 508-516.

Kind, P. R. N. and King, E. J. (1954). Estimation of plasma phosphatase by determination of hydrolysed phenol with amino-antipyrine. J. clin. Path., 7, 322-326.

Paton, A. (1969). Liver Disease, p. 48. Heinemann, London.
Pekarthy, J. M., Short, J., Lansing, A. I., and Lieberman, I. (1972). Function and control of liver alkaline phosphatase. J. biol. Chem., 247, 1767-1774.

Polin, S. G., Spellberg, M. A., Teitelman, L., and Okumura, $\stackrel{\vec{\oplus}}{+}$ M. (1962). The origin of elevation of serum alkalineo phosphatase in hepatic disease. Gastroenterology, 42, 431438.

Popper, H. and Szanto, P. B. (1956). Intrahepatic cholestasis $\frac{\mathcal{S}}{\Phi}$ ("cholangiolitis"). Gastroenterology, 31, 683-700.

Posen, S. (1967). Alkaline phosphatase. Ann. intern. Med., 67, 183-203.

Price, C. P., Hill, P. G., and Sammons, H. G. (1972). The $\vec{\circ}$ nature of the alkaline phosphatases of bile. J. clin. Path., 25, 149-154.

Price, C. P. and Sammons, H. G. (1974). The nature of the serum alkaline phosphatases in liver diseases. J. clin. 뭉 Path., 27, 392-398.

Price, C. P. and Woodman, D. D. (1971). An improved AutoAnalyzer technique for the determination of serum alkaline phosphatase. Clin. chim. Acta, 35, 265-271.

Wachstein, M. and Meisel, E. (1958). Substrate specific phosphatases at $\mathrm{pH} 7 \cdot 2$ in biliary obstruction and liver $\sigma$ cell damage. Arch. Path., 65, 449-459.

Walker, A. W. and Pollard, A. C. (1971). Observations on serum alkaline phosphatase electrophoretic patterns on polyacrylamide gel. Clin. chim. Acta, 34, 19-29.

Wieme, R. J. and Demeulenaere, L. (1970). Enzyme assays in liver disease. J. clin. Path., 24, Supplement (Ass. Clin. Path.), 4, 51-56.

Wootton, A. M., Neale, G., and Moss, D. W. (1975). Some properties of alkaline-phosphatases in parenchymal and $\vec{\bullet}$ biliary tract cells separated from rat liver. Clin. chim. Ac\&, 61, 183-190. 